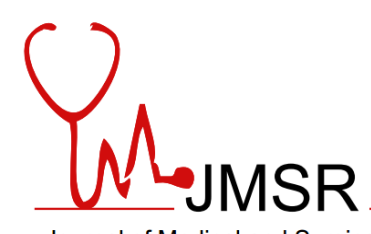

Journal of Medical and Surgical Research ISSN: 2351-8200

\title{
LIVER RESECTION FOR METASTASIS OF ADENOID CYSTIC CARCINOMA OF THE LACRYMAL GLAND: A CASE REPORT AND LITERATURE REVIEW
}

\author{
Chafik Bouzid ${ }^{1,4}$, Imène Haroun ${ }^{1,4}$, Mohand Kheloufi ${ }^{1,4}$, Aissam Chibane ${ }^{1,4}$, Zaki Boudiaf ${ }^{1,4}$, \\ Karim Cherchar ${ }^{1,4}$, Djamel Benabdelmoumène ${ }^{3,4}$, Hayat Ait Kaci ${ }^{2,4}$, kamel Bentabak ${ }^{1,4}$ \\ ${ }^{1}$ Department of Surgical oncology "A", Pierre \& Marie Curie Center, Algiers, Algeria. \\ ${ }^{2}$ Department of pathology. Pierre \&Marie Curie Center, Algiers, Algeria. \\ ${ }^{3}$ Department of radiology, Nafissa Hamoud hospital, Algiers, Algeria
}

${ }^{4}$ Benyoucef Benkhedda Algiers University, Algeria.

\begin{abstract}
ÁĀSTTRĀ $\overline{\mathbf{C}} \overline{\mathbf{T}}$
Adenoid cystic carcinoma (ACC) is a rare malignant tumor. The first description of the ACC dates back to 1856 by Billroth. The ACC of the lacrimal glands are very rare. They are known for their locally aggressive character. Liver metastases are almost exceptional. We report the case of a patient with hepatic metastasis ACC. After eye enucleation of the primitive lacrimal gland ACC, the patient received external adjuvant radiotherapy. Three years later, she presented an upper abdominal pain. CT scan and MRI showed a liver tumor and the diagnosis of intrahepatic cholangiocarcinoma was made regarding imaging features. A left hepatectomy was performed; histology concluded to a liver metastasis of ACC. The immediate post-operative course was uneventful and no adjuvant treatment was decided. Thirty four months later, the patient presented with lung metastasis.

Liver metastasis of ACC are very rare. Extended liver surgery is recommended especially for isolated liver metastasis with a long free gap between primary tumor and the liver metastasis.
\end{abstract}

Keywords: Adenoid cystic carcinoma; Hepatic metastasis; Lacrymal gland.

Corresponding Author:

Chafik Bouzid, MD

Address: Department of surgical oncology "A", Pierre and Marie Curie Center, Algiers, Algeria.

E-mail : chafikbouzid@yahoo.fr

Copyright $\odot$ 2012- 2021 Chafik Bouzid, et al. This is an open access article published under Creative Commons Attribution -Non Commercial- No Derives 4.0 International Public License (CC BY-NC-ND). This license allows others to download the articles and share them with others as long as they credit you, but they can't change them in any way or use them commercially.

doi: 10.46327/msrjg.1.000000000000---

*****Published in February 2021. doi url: https://doi.org/10.46327/msrjg

\section{INTRODUCTION}

The adenoid cystic carcinoma (ACC) represents less than $1 \%$ of tumors of the head and neck (1) and 1 to $2 \%$ of orbital tumors (2). The first description of the ACC dates back to 1856 by Billroth (3). It affects mainly the salivary glands and less frequently the lacrimal glands (4). The ACC of the lacrimal glands is characterized by a local malignancy. The infiltration of nervous nets is often found. The metastasis are rare, and when they exist, they include by order of frequency: Lungs, brain and bones. The hepatic metastases are rarely described, and exceptionally isolated. The resection of hepatic metastasis remains controversial (5). We report the case of a patient, carrier of a hepatic metastasis of a lacrymal ACC operated 04 years before.

\section{OBSERVATION}

In January 2011, a 63 years old female patient was diagnosed with a tumor of the right lacrymal gland tumor treated by eye enucleation. Histological study concluded to an ACC. The patient received an external 60 grays radiotherapy beam in postoperative.

Four years later, she performed an abdominal ultrasound, which revealed the presence of a heterogeneous liver mass within the left liver. The CT- scanner found an hypoattenuating mass on unenhanced CT (Figure 1), less enhancement than the surrounding liver on the arterial phase and become hyperattenuating than the parenchyma at the portal venous phase. Liver MRI was performed, found a huge polylobed left liver mass of $96 / 80 \mathrm{~mm}$ with high T2 signal intensity, centered by the bile 


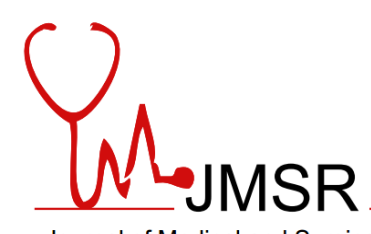

Journal of Medical and Surgical Research

ducts dilated, diffusion restriction on DWI, low T1 signal intensity with the same enhancement as on the CT scan. The diagnosis of intra hepatic cholangiocarcinoma has been strongly suspected.

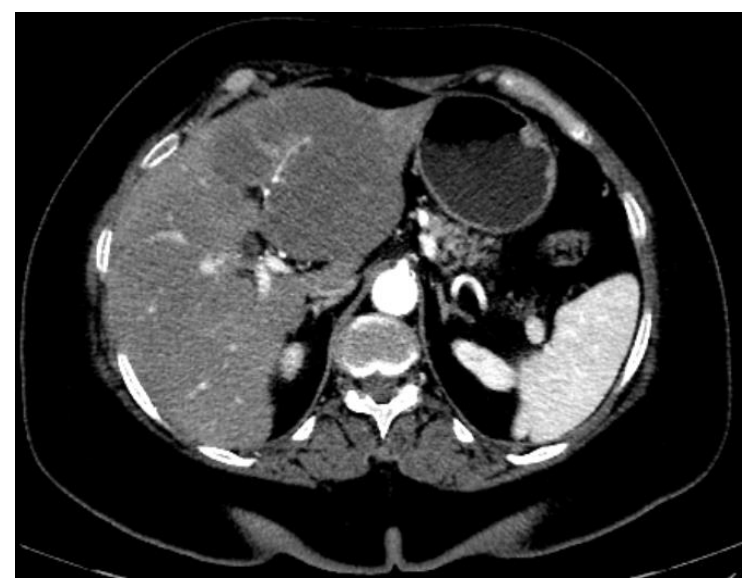

Figure 1: CT scan: CT arterial time: hypodense mass slightly enhanced, infiltrating appearance modifying the contours of the liver

A hepatic resection was indicated. A left hepatectomy was performed (figure 2). An extra glissonian control of the left pedicle was practiced and the liver resection was conducted without clamping.

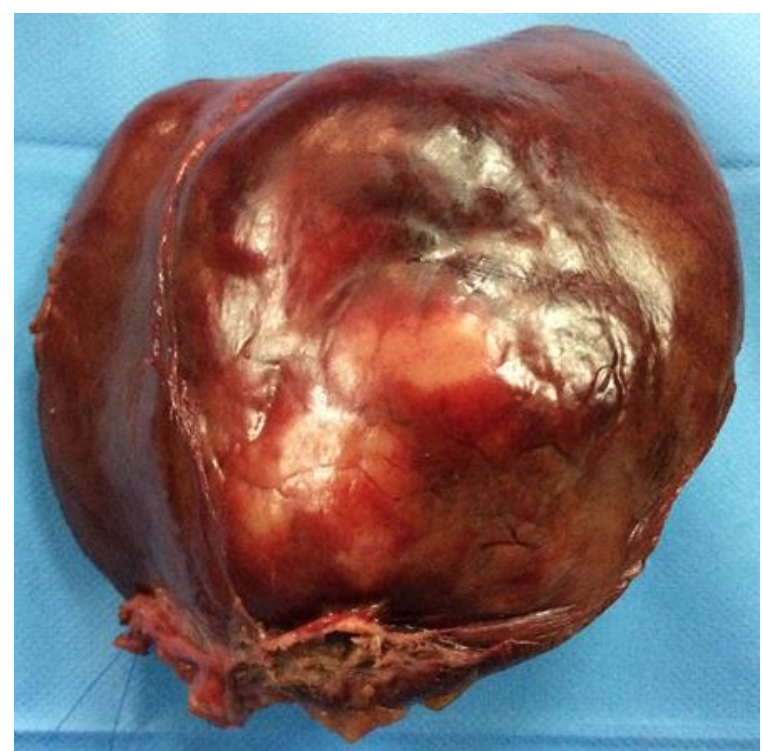

Figure 2: surgical specimen, left hemi-hepatectomy

The histological study found a neoplastic proliferation of a poorly limited epithelial nature made of hollow cavities clusters, of tubular structures and cords. The stroma was fibrous. Cytonuclear atypia were present as well as mitosis.
Immunohistochemistry showed a positivity of the tumor cells for the cytokeratin 7, the CD117 and the EMA were found. The Ki67 was $60 \%$. The final diagnosis was a hepatic metastasis of an ACC of the lacrymal gland. (Figures 3, 4)

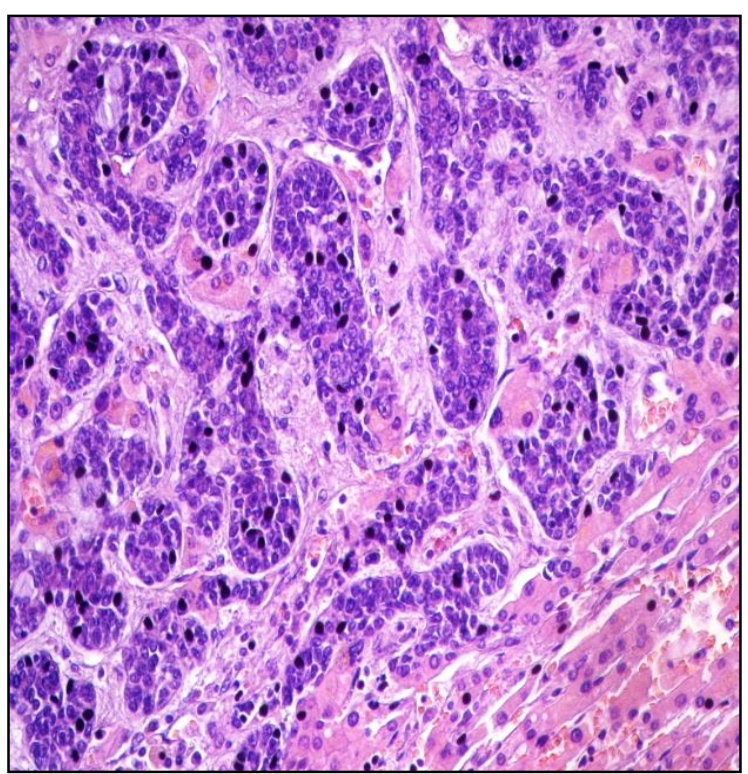

Figure 3: (HE x 200) : liver metastasis of ACC

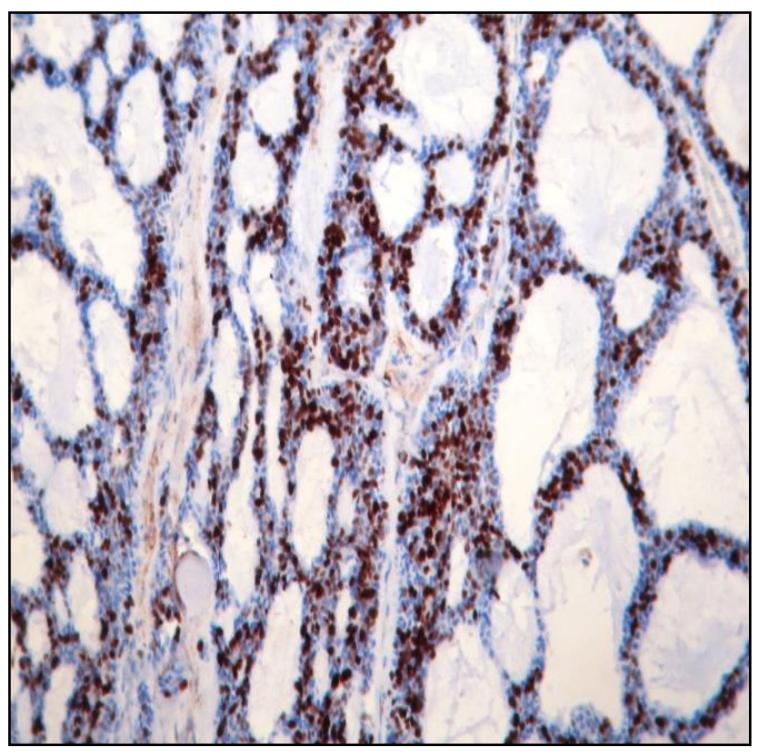

Figure 4: (IHC x 200): KI67 tumor cells' nuclear staining (> 60\%)

The patient was discharged after the $5^{\text {th }}$ postoperative day. Thirty four months post hepatectomy, the patient presented with symptomatic lung metastasis treated by sorafenib. She died 50 months after liver resection and 16 months after the diagnosis of lung metastasis. 


\section{UhomsR}

Journal of Medical and Surgical Research

\section{DISCUSSION}

The most common location of the ACC remains the salivary glands. They represent $10 \%$ of salivary carcinomas $[1,6]$. Isolated hepatic metastases have been rarely reported; they often present with multiple visceral metastases where only a medical treatment is possible [7]. For the best of our knowledge, we report the 9th liver resection for ACC metastasis published in English literature.

The evolution of these tumors is difficult to predict. Poor prognosis factors are the tumor size, the site of the primitive and the existence of metastases [8]. The index of tumor proliferation $\mathrm{Ki}-67$ could also have a prognosis value [9].

Given the rarity of these tumors, the studies reporting series of non-colorectal non-endocrine liver metastases didn't identify any case of hepatic metastasis of ACC [10]. In the multicenter series of
Adam et al [11] which include 1452 patients, only 15 patients had liver metastases of a primitive head and neck tumor. The main histological type in this patients' sub-group was the epidermoid carcinoma and the 05 years survival rate was less than $15 \%$. In our patient, the diagnosis of an ACC was done at the age of 63 and the hepatic metastasis appeared 46 months after the resection of the primitive tumor. The therapeutic strategy is not clearly defined [6]. In the literature, few cases of resection of liver metastasis of ACC have been reported. Zeidan et al [5], Sali et al [12] and Park et al. [13] reported a case of hepatic resection for ACC metastasis; the primitive was respectively a lacrimal ACC, parotid or sub-maxillary ACC and Tracheal ACC [5, 12, 13]. All published cases in the English literature are summarized in Table I. Authors were contacted by e-mail to update the patients' observations.

Table I: Summary of published cases with resection of hepatic metastasis of ACC

\begin{tabular}{|c|c|c|c|c|c|c|c|c|}
\hline Authors & Age & Sex & Primary Tm & Metastasis & $\begin{array}{l}\text { Delay } \\
\text { tm- Mt }\end{array}$ & Surgery & $\begin{array}{c}\text { Medical } \\
\text { treatment }\end{array}$ & Survival \\
\hline $\begin{array}{l}\text { Zeidan } \\
2006^{[5]}\end{array}$ & 51 & M & Lacrymal gland & $\begin{array}{l}\text { Right liver } \\
(20 \mathrm{~cm})\end{array}$ & $20 y$ & Right hemi hepatectomy & None & Lost to follow-up \\
\hline $\begin{array}{l}\text { Park } \\
2009 \text { [13] }\end{array}$ & 52 & $\mathrm{~F}$ & Trachea & $\begin{array}{l}\text { Segments } \\
\text { VIII, VII }\end{array}$ & $36 \mathrm{~m}$ & Right hemi hepatectomy & None & \\
\hline $\begin{array}{l}\text { Balducci } \\
2011\end{array}$ & 55 & M & Sub- maxillary & $\begin{array}{l}\text { Segments } \\
\text { VIII, V, VI }\end{array}$ & $18 \mathrm{~m}$ & Right extanded hepatectomy & $\begin{array}{l}\text { Cisplatin } \\
\text { Epirubicin }\end{array}$ & Died after $24 \mathrm{~m}$ \\
\hline $\begin{array}{l}\text { Coupland } \\
2014^{[6]}\end{array}$ & 52 & $\mathrm{~F}$ & Sub- maxillary & Segment V & $38 \mathrm{y}$ & sub segmentectomy $\mathrm{V}$ & None & $02 \mathrm{y}$ alive \\
\hline $\begin{array}{l}\text { Spolverato } \\
2014^{[1]}\end{array}$ & 59 & $\mathrm{~F}$ & Sub- maxillary & IV & $24 \mathrm{~m}$ & Left hemi hepatectomy & None & $05 \mathrm{~m}$ alive \\
\hline $\begin{array}{l}\text { Sali } 2016 \\
{[12]}\end{array}$ & 42 & $\mathrm{~F}$ & $\begin{array}{l}\text { Lacrymal } \\
\text { gland }\end{array}$ & $\begin{array}{l}\text { Segments } \\
\text { IVb \& VII } \\
\text { Lung Mt }\end{array}$ & $60 \mathrm{~m}$ & $\begin{array}{l}\text {-Right hemi hepatectomy } \\
\text { extended to segment IV b } \\
\text {-Lung metastasis resection }\end{array}$ & None & $18 \mathrm{~m}$ alive after lung surgery \\
\hline $\begin{array}{l}\text { Zemni I } \\
{[14]}\end{array}$ & 29 & $\mathrm{~F}$ & Parotid gland & Left liver & $60 \mathrm{~m}$ & Wedge resection & None & Alive \\
\hline $\begin{array}{l}\text { Present } \\
\text { Case }\end{array}$ & 63 & $\mathrm{~F}$ & $\begin{array}{l}\text { Lacrymal } \\
\text { gland }\end{array}$ & Left liver & $46 \mathrm{~m}$ & Left hemi hepatectomy & $\begin{array}{l}\text { Sorafenib after } \\
\text { lung metastasis }\end{array}$ & $\begin{array}{l}\text { recurrence at } 26 \mathrm{~m} \text { (lung } \\
\text { metastasis); Patient died after } 50 \\
\mathrm{~m} \text { of follow-up }\end{array}$ \\
\hline
\end{tabular}

M: Male; F: Female; Mt: metastasis; Tm: Tumor; m: months; y: years.

Considering the slow evolution of these tumors, many questions raised the benefit of the surgery and/or chemotherapy in this context especially that the metastases are often asymptomatic [14-16]. For the isolated liver metastasis, especially with free gap between the primitive and the metastasis, the surgery of resection was performed. Interesting survivals were reported in the published case reports which suggest the benefit of a surgical resection. Scuderi et al [8] reported re- hepatectomy after a unique metastatic recurrence. laparoscopic approach could be considered.
More free the gap between the primitive and the metastasis is important, better the prognosis is and the resection of the hepatic metastasis is justified. In the reported cases, the free gap ranged from 18 months to 38 years $[1,5-8,13]$. For our patient, the free gap between the primitive and the hepatic metastasis was 46 months. The definitive diagnosis lays on the histological study of the operative specimen using immunohistochemistry. Spolverato et al [1] reported a positivity in the cytokeratin 7, c-Kit, and EMA and a negativity for the PAX8, TTF-1, CDX2, CK20, chromogranin, 


\section{UnJMSR}

Journal of Medical and Surgical Research

synaptophisin, CD5, Hepar 1, the ER, and the p 63. A neo adjuvant chemotherapy with an association of pirubicin and cisplatin was suggested by Balducci and al [7]. The response to this protocol was poor and a hepatic resection was carried out afterwards. An adjuvant chemotherapy was also proposed by some authors but the benefit was not clearly established [5, 6]. Intra Arterial Cytoreductive Chemotherapy is now being considered as an adjuvant therapy of ACC to improve disease control after a primary surgical resection [12].

The prognosis after resection remains favorable. However, the fact that publications of cases of resection of hepatic ACC metastases are rare makes it that we cannot estimate the actual prognosis of this presentation.

\section{CONCLUSION}

Hepatic metastases of the ACC are rare. Surgery is proposed when the metastasis is isolated, a fortiori when there is a free gap between the primary tumor and the metastasis.

\section{ACKNOWLEDGMENTS:}

None.

\section{CONFLICTS OF INTEREST:}

The authors declare no conflict of interest

\section{REFERENCES}

1. Spolverato G, Fite $\mathbf{J}$, Bishop $\mathbf{J}$ et al. Liver metastasis as the initial presentation of Adenoid cystic carcinoma. Dig Dis Sci (2014) 59: 2004-2006.

2. Wright I, Pink GE, Garner H. Primary malignant neoplasms of the lacrimal gland. $\mathrm{Br} \mathrm{J}$ Ophthalmol 1992, 76: 401-407.

3. G. Papaspyrou, S. Hoch, A. Rinaldo et al. chemotherapy and targeted therapy in adenoid cystic carcinoma of the head and neck: a review. Head Neck 33 : 905-911, 2011.

4. Amit M, Binenbaum Y, Sharma K et al. Analysis of failure in patients with adenoid cystic carcinoma of the head and neck. An international collaborative study. Head Neck 36: 998-1004, 2014.

5. Zeidan BA, Abu Hilal M, Al-Gholmy $\mathrm{M}$ et al. Adenoid cystic carcinoma of the lacrimal gland metastasing to the liver: report of a case. World J Surg Oncol, 2006, 4: 66.

6. Coupland A, Sewpaul A, Steaks A et al. Adenoid cystic carcinoma of the submandibular gland, locoregional recurrence, and a solitary Liver metastasis More than 30 years since primary diagnosis. Check box Rep Surg. 2014; 2014:581823.

7. Balducci G, Sagnotta A, Muroni MR et al. An unusual case of exclusive liver metastases from adenoid cystic carcinoma of the submandibular gland: A Role for surgery? Report of a case. Surg Today (2011) 41 : 596599.

8. Scuderi V, Ceriello A, Romano $M$ et al. Recurrent adenoid cystic carcinoma in the liver: repeated laparoscopic surgical approach. Updates Surg (2011) 63 : 301-306.

9. Vacchi-Suzzi M, Bocciolini C, Bertarelli C et al. Ki-67 proliferation rate as a prognostic marker in major salivary gland carcinomas. Ann Otol Rhinol Laryngol (2010) 119(10) : 677-683.

10. Goéré D, Elias D. resection of liver metastases from colorectal non non-endocrine primary tumors. Eur J Surg Oncol 2008 ; 34(3) :281-8.

11. Adam R, Chiche $L$, Aloia $T$ et al. Hepatic resection for noncolorectal nonendocrine liver metastases. Ann Surg 2006 ; 244 : 524- 535.

12. Sali $P A$, Yadav KS, Bushan $K$ et al. A rare case of lacrimal adenoid cystic carcinoma with large hepatic and multiple pulmonary metastases with successful surgical treatment. Int J Surg Case Rep 20 (2016) 151-154.

13. Park I, Lim SN, Yoon DH et al. Metastasectomy for hepatic metastases from adenoid cystic carcinoma of the trachea. Gut and liver, Vol. 3, No. 2, June 2009, pp. 127 129.

14. Zemni I, Tounsi N, Bouraoui I et al. A single liver metastasis from adenoid cystic carcinoma of the parotid gland: case report. J Investig Med High Impact Case Rep. Jan-Dec 2019; 7: 2324709619879631.

15. Sun MW, Kim KH, Kim JW et al. Clinicopathologic predictors and impact of distant metastasis from adenoid cystic carcinoma of the head and neck. Arch Oto laryngol Head Neck Surg 2003 ; 129(11) :1193-7.

16. Spiro HR. Distant metastasis in adenoid cystic carcinoma of salivary origin. Am J Surg 1997 ; 174(5) :495-8. 